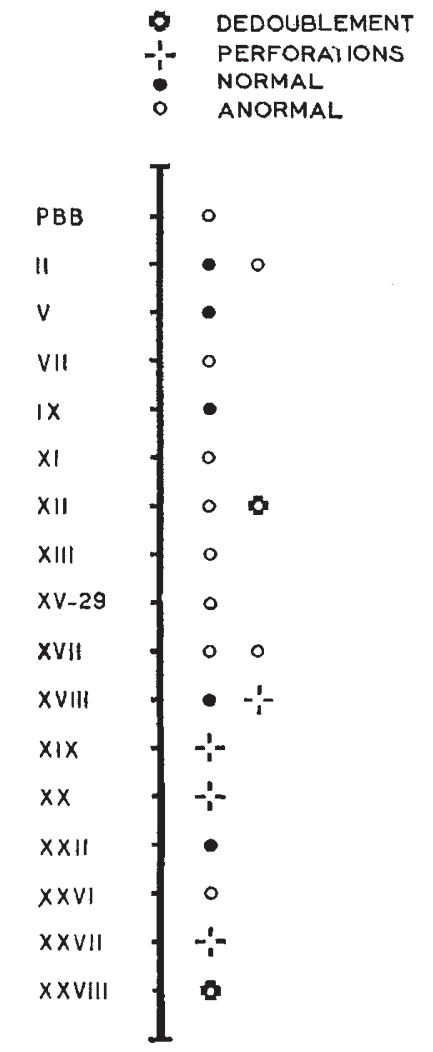

Fig. 3. Distribution of spina bifida according to the sepultures

It would also seem that there is an increase of that anomaly in time. The number of the tombs rather closely corresponds to the antiquity of the sepultures; we can see in Fig. 3 that from tomb XVIII to tomb XXVIII only one bone shows an actual dehiscence: this dehiscence is found in 9 sacra from tomb XVIII. This could suggest the diffusion of spina bifida by a dominant gene.

Denise Ferembach

Laboratoire d'Anthropologie Physique

de l'Ecole Pratique des Hautes Etudes, 1 rue René-Panhard, Paris, 13.

1 Paturet, G., Traité d'Anatomie humaine, 1 (Paris, 1951).

- Schmorl, G., and Junghans, $\mathrm{H}$., Clinique et radiologie de la colonne vertebrale (Paris, 1956).

- Pales, L., Paléopathologie et pathologie comparative (Paris, 1930).

- Doran, P. A., and Guthkelch, A. N., Lancet, 1, 296 (1961).

5 Gates, R. R., Human Genetics (New York, 1952).

- Neel, J. V., and Schull, W. J., Human Heredity (Chicago, 1954).

'Ferembach, D., Boletim da Sociedade Portuguesa de Ciencias Naturais, second series, 13,1 (1960).

\section{Criteria for the Comparison of Skulls}

THE two essentials for the satisfactory comparison of skulls are a common plane of orientation and a centring point that is universally valid, that is, common to all skulls throughout the vertebrate series. There is urgent need for agreement on these two criteria and particularly on a common centring point.

Many planes of orientation have been devised ${ }^{1-3}$; but it is now generally agreed that the Frankfurt Horizontal is the most satisfactory for primates, at least (but see ref. 3 ). There are, however, differing views on the centring point, with the basi-cranial angle as a possible favourite.

There is one point in all vertebrate skulls which can be looked on as a universally valid morphological featurethat is, the frontal extremity of the notochord. This lies just within or immediately behind the pituitary fossa in all vertebrates4. In man this end of the notochord is temporarily attached to the posterior lobe of the pituitary gland ${ }^{5}$. In the human being, and possibly in most vertebrates, the frontal extremity of the notochord is finally encased in the posterior wall of the pituitary fossa. The posterior lobe of the pituitary gland or, more readily, the pituitary fossa should, therefore, provide a good common centring point for all skulls. It has the advantage, too, that it remains constant throughout the age-range of any animal.

If skulls are centred on the pitaitary fossa (in practice the floor of the fossa is the most convenient point to choose) and orientated in the Frankfurt Horizontal an interesting series of relationships emerges.

In all humar beings examined, of diverse ethnic origin (European, Chinese, Australian aborigine) and of ages ranging from neonatus to adult, the Frankfurt Horizontals were virtually coincident at the level of the inferior surface of the body of the sphenoid bone. In other primates (Gorilla, Pan, Pongo, Macaca, Papio) and a juvenile macaque (about six months old) the Frankfurt Horizontals were also virtually coincident but at a much higher level which crossed the middle of the pituitary fossa. A quadruped skull (Ovis aries) was examined on the same criteria and the Frankfurt Horizontal was found to be still higher, passing just above the pituitary fossa. Moreover, it could be shown that the level of the Frankfurt Horizontal was in each case related to the plane of the foramen magnum and hence to the angle at which the skull joined the vertebral column ${ }^{6}$. Use of the region about the frontal extremity of the notochord has, therefore, encouraging morphological justification.

Comparison of skulls on this basis offers no difficulty if they can be sectioned in the modian sagittal plane. If they must be kept intact the pituitary fossa can usually be visualized satisfactorily in orthogonal or near-ortho. gonal X-ray plates. Should the radiographic detail be confusing - as it is in some of the larger apes-or obscured by mineralization the pituitary fossa can be identified by inserting a thin strip of lead through the foramen magnum and hooking it over the dorsum sellæ.

Some skulls are too heavily mineralized even for this expedient and many are so filled with dense matrix as to render the mancuvre impossible. Under such circum. stances an alternative is sometimes available.

The correlative of the posterior lobe of the pituitary gland is the anterior lobe which migrates from the dorsal wall of the naso-pharynx as the pouch of Rathke to reach the pituitary fossa. The point of departure from the naso-pharynx is where the posterior border of the root of the vomer joins the body of the sphenoid. This point is frequently marked by a pit on the underside of the sphenoid. It is called the 'hormion' in physical anthro. pology. It serves as a useful substitute for the pituitary fossa as a common cranial centre and can be used in heavily mineralized skulls and in skulls solidly filled with matrix provided the region is clean and intact. The hormion can even be used on casts if they are accurately made. The hormion is not quite so accurate as the pituitary fossa because the depth of the body of the sphenoid varies from skull to skull but it is certainly more precise than most of the centring points utilized so far.

Department of Anatomy,

A. A. ABBIE

University of Adelaide.

${ }^{1}$ Wilder, H. H., A Laboratory Manual of Anthropometry (Blakiston, Phila-

delphia, 1920).
Keith, A., The Antiquity of Man (Williams and Norgate, London, 1929).

selattre, A., and Fenart, R., L'Hominisation du Crane (Ad. Cent. Nat. Réch. Sci., 1960).

' de Beer, G. R., The Development of the Vertebrate Skull (Clarendon Press, Oxford, 1937).

- Patten, B. M., Human Embryology, second ed. (McGraw-Hill, New York, 1953).

- Abbie, A. A., Z. Anthrop. Morph. (in the press). 